\title{
Allergic Bronchial Asthma Due to Dermatophagoides pteronyssinus Hypersensitivity Can Be Efficiently Treated by Inoculation of Allergen-Antibody Complexes
}

\author{
Jacques J. Machiels, ${ }^{\star}$ Michel A. Somville, ${ }^{\ddagger}$ Philippe M. Lebrun, ${ }^{\ddagger}$ Serge J. Lebecque, ${ }^{\ddagger}$ \\ Marc G. Jacquemin, ${ }^{\ddagger}$ and Jean-Marie R. Saint-Remy ${ }^{\ddagger}$ \\ ${ }^{*}$ Chest Disease Unit, Internal Medicine Department, Clinique Saint-Pierre, 1340 Ottignies, Belgium; and ${ }^{\ddagger}$ Experimental Medicine \\ Unit, Institute of Cellular and Molecular Pathology, Université Catholique de Louvain, 1200 Brussels, Belgium
}

\begin{abstract}
Antigen-antibody complexes were made from allergens of the common house dust mite, Dermatophagoides pteronyssinus (Dpt) and an excess of purified autologous specific antibodies. These complexes have been used to treat Dpt-hypersensitive patients who suffered from chronic bronchial asthma. Clinical symptoms and medication intake were followed by filling in diary cards. Peak expiratory flow, measured four times a day, was also followed. Intradermal skin tests and bronchial challenge tests were performed with allergen together with an evaluation of nonspecific bronchial reactivity. Specific IgE and IgG antibodies were assayed after separation from the bulk of serum immunoglobulins by immunoadsorption. The study was carried out over two years according to a double-blind protocol.

Intradermal inoculation of antigen-antibody complexes resulted in a marked reduction of both clinical and medication scores. No systemic side-effects were observed and only mild wheal and flare reactions were noted at the injection site. The treatment showed a drastic reduction of specific skin and bronchial reactivities with only marginal effects on nonspecific bronchial reactivity. Concentrations of specific IgE antibodies decreased significantly during the first weeks of treatment and remained at these lower values throughout the study. Specific IgG antibodies actually decreased in the majority of treated patients. The total amount of allergen used in this study was $<1 \%$ of the amount currently used for conventional hyposensitization with the same allergen.
\end{abstract}

These findings show that antigen-antibody complex inoculation is an efficient and safe means of treating allergic bronchial asthma and that the mechanism of action is likely to differ from conventional hyposensitization. (J. Clin. Invest. 1990. 85:1024-1035.) atopy • house dust mite • immediate hypersensitivity • immune complexes $\bullet$ immunotherapy

\section{Introduction}

Ever since it was established that IgE antibodies play a central role in immediate hypersensitivity (1), suppression of its production has been a desirable therapeutic objective. Recent

Address correspondence to Dr. Jean-Marie Saint-Remy, Experimental Medicine Unit, Institute of Cellular and Molecular Pathology 7430, Université Catholique de Louvain, avenue Hippocrate 74, 1200 Brussels, Belgium.

Received for publication 19 April 1989 and in revised form 9 October 1989.

J. Clin. Invest.

(C) The American Society for Clinical Investigation, Inc.

$0021-9738 / 90 / 04 / 1024 / 12 \$ 2.00$

Volume 85, April 1990, 1024-1035 work on IgE regulation has raised the possibility of isotypic suppression (2), but the practical implications of such an approach remain unclear. Suppression of allergen-specific IgE could provide advantages in this respect, but to date attempts to achieve this have been inconclusive. Chemical modification of allergens generates compounds with increased immunogenicity but little, if any, effect on IgE production (3). Tolerogens, such as allergens covalently coupled to isologous immunoglobulins (4), are effective in suppressing an IgE immune response in some, but not all animal species.

Antigen-antibody complexes could offer a valuable alternative procedure to suppress $\mathrm{IgE}$ antibody production. $\mathrm{Nu}$ merous papers on the use of complexes in experimental animals have appeared (5) and been reviewed (6). Both enhancement (7) or suppression (8) of immune response have been described. However, specific conditions under which complexes are suppressive can be defined. For example, excess of isologous IgG antibodies usually yields such complexes (9).

The IgE immune response presents several advantages for the evaluation of the suppressive effects of antigen-antibody complexes. First, experimental work in rodents has shown that IgE production is more easily controlled than other isotypes (10). Second, IgE-mediated diseases have long been treated in humans by regular injections of allergen, a treatment associated with increased IgG antibody production (11). Therefore, if instead of the hoped-for suppression of specific IgE by antigen-antibody complexes, a stimulation of specific IgG antibodies occurred via increased allergen immunogenicity, then it could be argued that this could be beneficial to the patient in any case.

We recently isolated anti-allergen antibodies from the serum of patients hypersensitive to the common house dust mite Dermatophagoides pteronyssinus $(\mathrm{Dpt})^{1}(12)$. These antibodies can be used for the preparation of soluble complexes made in antibody excess after addition of allergen. We report here the results of a trial in Dpt-hypersensitive bronchial asthma patients, the specific aim of which was to determine whether inoculation of allergen-antibody complexes can result in a decrease of IgE antibody production. Due to ethical considerations, we selected a population of patients who suffered from chronic bronchial asthma exacerbated by allergen exposure and in whom conventional hyposensitization had failed. These chronically ill patients required daily medication for their asthma. Therefore, as a monitor of the efficacy of antigen-antibody complex inoculation, we decided to use any reduction in the medication (particularly corticosteroid intake)

1. Abbreviations used in this paper: Ach, acetylcholine; Dpt, Dermatophagoides pteronyssinus; FEV1, forced expiratory volume in one second; PEF, peak expiratory flow. 
necessary for the maintenance as far as possible of a symptom-free state.

The results of the clinical trial can be summarized as follows: $(a)$ virtual absence of side effects; $(b)$ reduction in medication intake with no further need for oral corticotherapy; $(c)$ early improvement of symptoms in almost every patient; $(d)$ reduction in skin reactivity to allergen testing; $(e)$ disappearance of specific bronchial reactivity in $50 \%$ of the patients with unchanged nonspecific reactivity; $(f)$ early decrease in IgE antibody concentrations; and $(g)$ absence of specific IgG antibody increase.

\section{Methods}

Patient selection. 39 patients ( 25 males and 14 females; average age 33 $\mathrm{yr}$, range 16-57 yr) gave their informed consent for participation in this study. The following criteria were used for inclusion in the trial: $(a)$ chronic bronchial asthma severe enough to require daily treatment with inhaled beta ${ }_{2}$-agonists and inhaled beclomethasone, and regular courses of oral corticosteroids (patients with systemic corticodependence were excluded, however); (b) Dpt hypersensitivity as evidenced by clinical history, skin prick test, radioallergosorbent test $(4+)$ and specific bronchial challenge, and significant exacerbation of asthma by allergen exposure; and $(c)$ unsuccessful hyposensitization with Dpt, defined as regular inoculations of allergen, in soluble or alum-adsorbed form, for at least $2 \mathrm{yr}$. The mean time interval since the last desensitization was $7.2 \mathrm{yr}$. With regard to other allergic sensitivities, eight patients were found to be sensitive to cat allergens (three in group $A$, three in group $B$, and two in group $C$ ), three were sensitive to grass pollen (one in group $\mathrm{A}$ and two in group $\mathrm{C}$ ), one patient in group $\mathrm{A}$ was sensitive to Alternaria tenuis, and one patient in group $\mathrm{C}$ was sensitive to Cladosporium herbarum. The number of patients sensitive to mite allergens alone was 27 ( 9 in group A, 10 in group B, and 8 in group C). All patients had been followed up in our Chest Disease Unit for at least 6 mo before the beginning of the study, during which time they were instructed in basic procedures for minimizing domestic allergen exposure. The study was approved by the University Ethical Committee.

Dpt allergens. A glycerinated extract of Dpt, purchased from Bencard Ltd. (Epsom, Surrey, UK), was dialyzed extensively against PBS, pH 7.4, containing $100 \mathrm{U}$ aprotinin/ml as proteolysis inhibitor (12), and concentrated to $3 \mathrm{mg} / \mathrm{ml}$ by ultrafiltration on a YM10 membrane (Amicon Corp., Danvers, MA). SDS-PAGE showed three main protein bands with molecular masses of 15,26 , and $47 \mathrm{kD}$. Der $p 1$ was identified in the middle band by immunoelectrophoresis (courtesy of Dr. P. Lind, Copenhagen, Denmark) and accounted for $60 \%$ of total protein. Allergen preparations were stored at $-80^{\circ} \mathrm{C}$ until just before use. The same allergen batch was used for immunoadsorption, allergen-antibody complex preparation, bronchial challenge, and skin testing. Allergen concentrations are given in total protein content measured by absorption at $280 \mathrm{~nm}$ with $\mathrm{E}_{1 \%}=10$, and $1 \mathrm{ng}$ of protein corresponding to 0.25 Noon unit.

Specific antibodies. Specific anti-Dpt antibodies were prepared from the serum of Dpt-hypersensitive patients by salt precipitation, gel filtration, and adsorption on insolubilized Dpt-allergens (12). In brief, $50 \mathrm{ml}$ of serum was precipitated by addition of an equal volume of 360 $\mathrm{g} \mathrm{Na}_{2} \mathrm{SO}_{4} /$ liter. After centrifugation, the precipitates were resuspended, dialyzed, and separated into IgM- and IgG-containing fractions by gel filtration chromatography. Dpt allergens were insolubilized on $\mathrm{CH}$ Sepharose (Pharmacia, Uppsala, Sweden) after carbodiimide activation, using $1 \mathrm{mg}$ protein/ml Sepharose. The IgG fraction from each patient was passed onto $5 \mathrm{ml}$ of packed Sepharose. After washing, adsorbed antibodies were recovered by elution with $50 \mathrm{mM}$ citric acid, pH 2.7. IgG antibodies in the eluates were evaluated by a sandwich ELISA with anti-human Fc $\gamma$ goat IgG and purified biotin-conjugated anti-human $\mathrm{Fc} \gamma$ goat IgG (both from Tago Inc., Burlingame, CA). IgA was quantified with an anti-human Fc $\alpha$ goat IgG (Tago Inc.) and a biotin-conjugated mouse monoclonal antibody to human Fc $\alpha$ which was developed in our laboratory. IgE antibodies were evaluated by agglutination of latex particles coated with anti-human Fce rabbit IgG (13). Isotypic distribution of specific antibodies showed a mean proportion of $85 \% \mathrm{IgG}, 15 \% \mathrm{IgA}$, and $0.1 \%$ IgE. Subtypes of IgG were assayed by radial immunodiffusion with anti-human $\mathrm{Fc} \gamma 1,-\gamma 2,-\gamma 3$, and $-\gamma 4$ sheep antibodies according to the supplier's instructions (Red Cross Central Laboratory, Amsterdam, The Netherlands). Distribution of IgG subtypes were as follows: $33 \%$ IgG1, 50\% IgG2, 7\% IgG3, and $10 \%$ IgG4.

Preparation of allergen-antibody complexes. The allergen-antibody ratio was calculated for every 'patient using an ELISA in which the binding of specific antibodies to insolubilized allergens was inhibited by allergen dilutions. Specific antibodies from individual patients were first labeled with biotin. $10 \mu \mathrm{l}$ of $N$-hydroxysuccinimido- $L C$-biotin (Pierce Chemical Co., Rockford, IL), freshly diluted to $10 \mathrm{mg} / \mathrm{ml}$ in dimethylformamide, was added to $0.5 \mathrm{ml}$ of $200 \mu \mathrm{g} / \mathrm{ml}$ antibodies in PBS. The solution was mixed for $2 \mathrm{~h}$ at $21^{\circ} \mathrm{C}$, dialyzed against $9 \mathrm{~g} / \mathrm{liter}$ $\mathrm{NaCl}$, and then diluted vol/vol in glycerol for storage at $-20^{\circ} \mathrm{C}$.

Polystyrene microtitration plates (Nunc, Roskilde, Denmark) were coated with $100 \mu \mathrm{l}$ of $10 \mu \mathrm{g} / \mathrm{ml}$ Dpt allergens in PBS, incubated $3 \mathrm{~h}$ at $21^{\circ} \mathrm{C}$, and washed three times with PBS containing $0.1 \%$ Tween-20 (Technicon Instruments Corp., Tarrytown, NY). The plates were then incubated for $2 \mathrm{~h}$ at $21^{\circ} \mathrm{C}$ with $200 \mu \mathrm{l} /$ well of $10 \mathrm{mM}$ Tris (hydroxymethyl)aminomethane, $\mathrm{pH} 7.3$, containing $9 \mathrm{~g} /$ liter $\mathrm{NaCl}, 5 \mathrm{~g} /$ liter casein (Aldrich Chemical Co., Milwaukee, WI), and $0.02 \%$ thimerosal (Sigma Chemical Co., St. Louis, MO) (casein buffer), and washed again as above. Biotin-labeled specific antibodies were diluted in casein buffer to concentrations varying from 20 to $0.1 \mu \mathrm{g} / \mathrm{ml}$ and a $100-\mu l$ aliquot of each dilution was added to the plate for an incubation of $4 \mathrm{~h}$ at $21^{\circ} \mathrm{C}$. The plates were washed with PBS-Tween and supplemented with $100 \mu \mathrm{l} /$ well of avidin-peroxidase (Sigma Chemical Co.) diluted to $1 \mu \mathrm{g} / \mathrm{ml}$ in PBS containing $5 \mathrm{~g} /$ liter BSA. After $30 \mathrm{~min}$ at $21^{\circ} \mathrm{C}$ and a further wash, $100 \mu \mathrm{l}$ of 2,2'-azino-bis(3-ethylbenzthiazoline)sulfonic acid (ABTS; Sigma Chemical Co.) diluted to $0.02 \%$ in $8 \mathrm{mM}$ $\mathrm{Na}_{2} \mathrm{HPO}_{4}, 6 \mathrm{mM}$ citrate buffer, $\mathrm{pH} 5.0$, and containing $0.03 \% \mathrm{H}_{2} \mathrm{O}_{2}$, was added. After $15 \mathrm{~min}$ in the dark at $21^{\circ} \mathrm{C}$ the plates were read at 405 $\mathrm{nm}$ with a Kontron 210 spectrophotometer (SLT-Lab Instruments, Salzburg, Austria).

The concentration of biotin-labeled specific antibodies that yielded $80 \%$ of the maximum binding to the plate was used for inhibition assays. It corresponded to an average of $1 \mu \mathrm{g} / \mathrm{ml}$ in each case. Dpt was

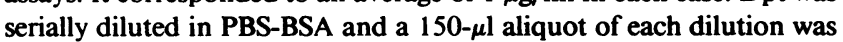
mixed for $30 \mathrm{~min}$ at $37^{\circ} \mathrm{C}$ with an equal volume of $2 \mu \mathrm{g} / \mathrm{ml}$ biotin-labeled specific antibodies. $100 \mu \mathrm{l}$ of this mixture was then added to Dpt-coated plates for $4 \mathrm{~h}$ at $21^{\circ} \mathrm{C}$, followed by washing and addition of avidin-peroxidase and ABTS as described above. The concentration of Dpt at which the binding of specific antibodies was inhibited by $20 \%$ was chosen to calculate allergen/antibody ratios. This ratio (wt/wt) varied from 1:20 to $1: 1$ for the different patients, with a mean value of 1:5 which was chosen for immunotherapy. Specific anti-Dpt antibodies of a single patient were diluted to $40 \mu \mathrm{g} / \mathrm{ml} \mathrm{in} 3 \mathrm{ml}$ of sterile saline $(9$ $\mathrm{g} /$ liter $\mathrm{NaCl}$ ) containing $0.3 \%$ human serum albumin and $0.4 \%$ phenol. An equal volume of $8 \mu \mathrm{g} / \mathrm{ml}$ Dpt-allergens diluted in the same buffer was added and the solution was mixed for $30 \mathrm{~min}$ at $37^{\circ} \mathrm{C}$. Single-use vials were prepared and stored at $-80^{\circ} \mathrm{C}$ until immediately before use.

Study design. Patients were randomly allocated to one of three groups and, in view of the limited number of patients, randomization adequacy was confirmed for age, sex, skin tests, duration, and severity of asthma (Mann-Whitney U test, $P=$ NS in each case). Asthma severity was first evaluated by daily monitoring of symptom and medication scores (see below) for at least $6 \mathrm{wk}$ before the study. The 13 patients of group $A$ were inoculated with gradually increasing amounts of antigen-antibody complexes of Dpt allergens and autologous antiDpt antibodies at a ratio of $1: 5(\mathrm{wt} / \mathrm{wt}$ ) (see Table I for details of the injection schedule and amounts injected). The 13 patients in group $B$ also received increasing amounts of $1: 5$ antigen-antibody complexes for the first five injections, after which the subsequent injections were 
Table I. Quantities of Antigen and Specific Autologous Antibody Used for the Treatment of Group A and Group B Patients

\begin{tabular}{|c|c|c|c|c|}
\hline \multirow[b]{2}{*}{ Week } & \multicolumn{2}{|c|}{ Group A } & \multicolumn{2}{|c|}{ Group B } \\
\hline & Antibody & Antigen & Antibody & Antigen \\
\hline & $\mu g$ & $n g$ & $\mu g$ & $n g$ \\
\hline 0 & 0.04 & 8 & 0.04 & 8 \\
\hline 2 & 0.08 & 16 & 0.08 & 16 \\
\hline 4 & 0.16 & 32 & 0.16 & 32 \\
\hline 6 & 0.20 & 40 & 0.20 & 40 \\
\hline 8 & 0.40 & 80 & 0.40 & 80 \\
\hline 10 & 0.40 & 80 & 0.40 & 80 \\
\hline 12 & 0.40 & 80 & 0.40 & 80 \\
\hline 14 & 0.60 & 120 & 0.40 & 80 \\
\hline 16 & 0.80 & 160 & 0.40 & 80 \\
\hline 18 & 1.20 & 240 & 0.40 & 80 \\
\hline 20 & 1.60 & 320 & 0.40 & 80 \\
\hline 22 & 2.00 & 400 & 0.40 & 80 \\
\hline 24 & 2.40 & 480 & 0.40 & 80 \\
\hline 26 & 2.80 & 560 & 0.40 & 80 \\
\hline 28 & 3.20 & 640 & 0.40 & 80 \\
\hline 52 & 3.20 & 640 & 0.40 & 80 \\
\hline Total (first year) & 51.48 & 10,296 & 9.28 & 1,856 \\
\hline Total (second year) & 25.60 & 5,120 & 3.20 & 640 \\
\hline
\end{tabular}

After the 28th treatment week, doses of complexes were kept constant and given at 14-d intervals until the end of the first year, after which they were administrated every $6 \mathrm{wk}$. Total amounts of injected material are also given for each treatment year.

given at this maintenance dose. Group $\mathrm{C}$ comprised 13 patients inoculated with albumin buffer alone. The maximum volume of each inoculate was $100 \mu \mathrm{l}$ given intradermally in the upper arm by the same physician (J.M.) who was unaware of the treatment regimen group to which the patients belonged. The study began in September 1985 and lasted till November 1987; the first injections were made in November 1985 and all patients were seen within the same week. During the first year of treatment the patients were inoculated every other week and for the second year, every six weeks.

Clinical evaluation. Patients were asked to fill in a diary card evaluating diurnal and nocturnal asthma, morning breathlessness, and cough on a discontinuous intensity score from 0 to 4 (14). Another score used for evaluation of medication intake was: 0 , no medication; 1 , inhaled bronchodilators (salbutamol) when required or twice daily; 2, regular bronchodilator intake, with or without theophylline; 3, inhaled beclomethasone; and 4, oral corticotherapy. Patients were instructed in the way to adapt their drug treatment according to both symptom scores and peak expiratory flow (PEF) measured before medication (minimum PEF). Inhaled beclomethasone or oral corticosteroids were added to the treatment when minimum PEF was $<80$ or $<60 \%$ of expected values, respectively.

Lung function and bronchial challenges. Vital capacity, forced expiratory volume in $1 \mathrm{~s}$ (FEV1), total lung volume, and specific airway conductance were measured at the beginning and after 1 and $2 \mathrm{yr}$ of treatment using a Jaeger ${ }^{\circledR}$ plethysmograph (Jaeger, Würsburg, FRG). In addition, each patient recorded his PEF with a peak-flow monitor (Vitalograph Ltd., Buckingham, UK) four times a day, before and after medication, in the morning and at night. Nonspecific and specific bronchial hyperreactivities were measured on two consecutive days after acetylcholine (Ach) or Dpt-allergen inhalation, respectively (15). Before evaluation of lung function, medication was discontinued for at least $12 \mathrm{~h}$ for beta ${ }_{2}$-agonists, $2 \mathrm{wk}$ for inhaled beclomethasone, and 2 mo for oral corticosteroids. Provocation tests were not performed when the basal lung function was $<75 \%$ of normal values. $1-\mathrm{ml}$ solutions containing either Ach or Dpt allergens were aerosolized in a 100 $\times 5.5 \mathrm{~cm}$ cylinder through a Bird $^{\circledR}$ micronebulizer (Bird Product Corp., Palm Springs, CA) generating particles of 0.5-5 $\mu \mathrm{m}$ diameter at a flow rate of 7-8 liters/min. The patient completely inhaled the aerosol by tidal volume breathing. FEV1 and airway conductance were evaluated immediately afterwards for Ach or 15 min after inhalation for Dpt allergens. A solution containing either $1 \mu \mathrm{g} / \mathrm{ml}$ Ach or 100 $\mathrm{pg} / \mathrm{ml} \mathrm{Dpt} \mathrm{freshly} \mathrm{prepared} \mathrm{by} \mathrm{dilution} \mathrm{of} \mathrm{a} 100 \mu \mathrm{g} / \mathrm{ml}$ stock solution was used as initial aerosol. Concentration of either reagent was increased by $10^{-0.5}$ every 30 min until a reduction of at least $20 \%$ in FEV 1 or $35 \%$ in airway conductance was measured.

Skin testing. Four solutions containing $400,100,25$, or $6.25 \mathrm{ng} / \mathrm{ml}$ Dpt allergens were prepared in albumin buffer and $20 \mu \mathrm{l}$ was inoculated into the skin of the patient's back with a 1-ml syringe and a 26-gauge needle. Mean wheal diameters were measured after $20 \mathrm{~min}$. A $1 \mathrm{mg} / \mathrm{ml}$ histamine solution was used to evaluate skin reactivity.

Antibody analysis. A 10-ml blood sample was taken at each patient's visit. Specific anti-Dpt antibodies were prepared by immunoadsorption onto a column to which allergens had been covalently coupled (see above). Depletion of the antibodies from the sample was confirmed by the absence of residual anti-Dpt antibodies in the flowthrough fractions. Adsorption of each patient's samples was performed in a random order to avoid any bias due to possible loss of columncoupled antigen. Isotypic distribution of eluted antibodies was determined by specific ELISA with a sensitivity of $1 \mathrm{ng} / \mathrm{ml}$ for IgG and 100 $\mathrm{pg} / \mathrm{ml}$ for IgE and a coefficient of variation of $<7 \%$ in both cases (12). The amount of specific antibodies was expressed as concentration in the original serum samples.

Statistical analysis. Clinical and medication scores and PEF were averaged over 2-wk periods to smooth individual variations. Nonparametric tests (Mann-Whitney U test and Wilcoxon matched pair test) were used except for correlations between log-transformed specific IgE and IgG antibody concentrations, which were carried out by a parametric test.

\section{Results}

Compliance and side-effects. 36 patients completed the 2-yr study. One patient did not begin the trial and two other patients, one in group A and one in group C, were lost for follow-up for unknown reasons. Two patients were seen less regularly than scheduled during the second year of treatment but were nevertheless maintained in the study. More than 800 injections were performed without any indication of systemic side-effects. An immediate skin reactivity to inoculation together with minor local pruritus was observed in 10 of the 26 patients treated. The wheal size was moderate $\left(0.5-2 \mathrm{~cm}^{2}\right)$ in all but two patients where it attained a maximum of $10.8 \mathrm{~cm}^{2}$. These skin reactions occurred only at the early stages of the injection regimen, and after the second month of treatment these patients could not be distinguished from the others on this basis. The patients who presented an initial skin reactivity were those for whom the calculated allergen-antibody ratio was $<1: 5$, indicating that free allergen was present in the solution used for inoculation. Inoculation of the carrier buffer produced an erythema and pruritus in two placebo patients. At the end of the study, patient group allocation (treated vs. placebo) was correctly guessed by the physician (J.M.). Each of the treated patients recognized the benefit of the therapy, whereas one-third of placebo patients thought they were given active treatment.

Symptom scores. Symptoms were recorded by the patients with the help of diary cards. A discontinuous scale was used to 
GroupA

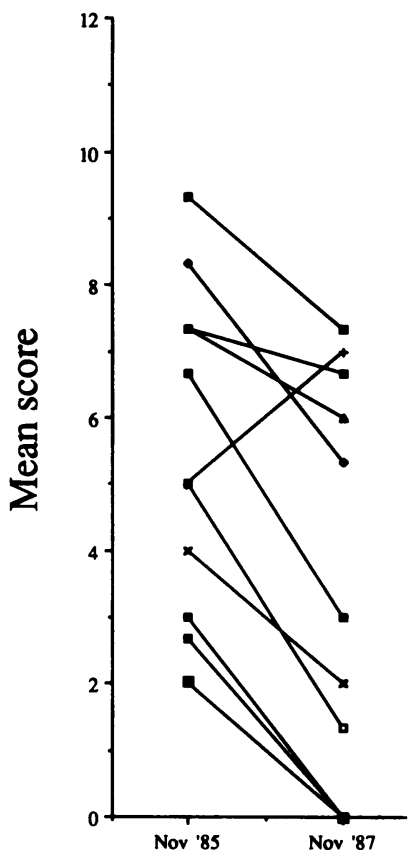

Group B

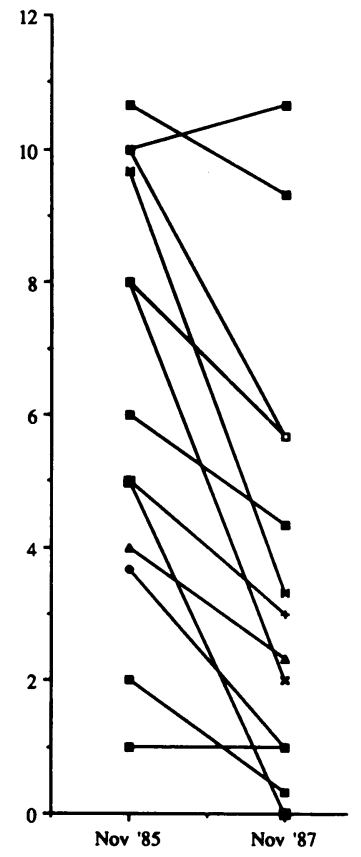

Placebo

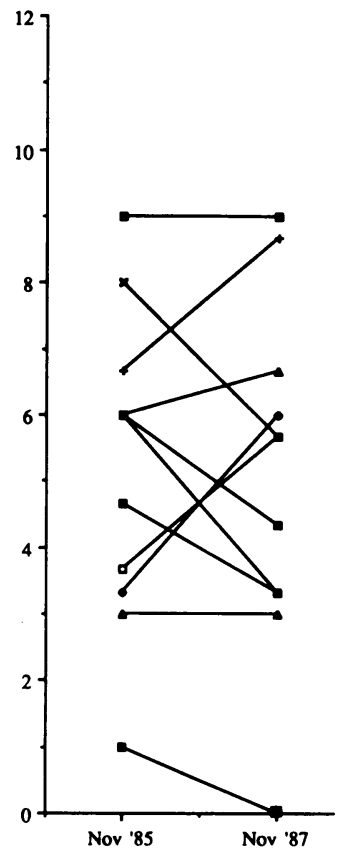

Figure 1. Individual changes in mean symptomatic scores between the beginning and end of the study period. Each point represents the mean of four symptom scores (diurnal asthma, nocturnal asthma, morning breathlessness, and cough) averaged over a 2 -wk period just before the beginning of treatment and $2 \mathrm{yr}$ afterward. monitor nocturnal and day-time asthma, cough, and morning breathlessness. First signs of clinical improvement were seen after the 10th week of treatment and reached a steady state after an average of six months. This benefit persisted through the second year of treatment. Fig. 1 shows the pattern of individual scores over two years. Each score represents the mean of symptoms over the two weeks just before the trial and exactly two years afterward. It should be recalled that each of these patients needed and took daily medication, yet despite this presented elevated symptom scores. No significant variation in symptoms of group C patients was seen, while in both groups $A$ and $B$ all but two patients improved (Wilcoxon matched pair test, $P<0.001$ ). No significant difference was seen between groups at the start of the study.
Medication scores. Drug intake was monitored on diary cards using a discontinuous scale. To facilitate analysis, patients were allowed access to only a limited number of drugs, namely salbutamol and beclomethasone in pressurized aerosols, and methylprednisolone in tablets. No significant difference in medication intake was observed between groups in the prestudy monitoring of the patients. Fig. 2 shows the evolution of medication intake over the first year of treatment. For the sake of clarity, the mean drug intake over the six weeks before the trial was arbitrarily designated as 100 . The first significant reduction in medication was seen round about the 18 th week and continued to improve thereafter in both groups A and B (Wilcoxon matched pair test, $P<0.001$ ), while drug intake actually increased in group $C$. This reduction was well illus-

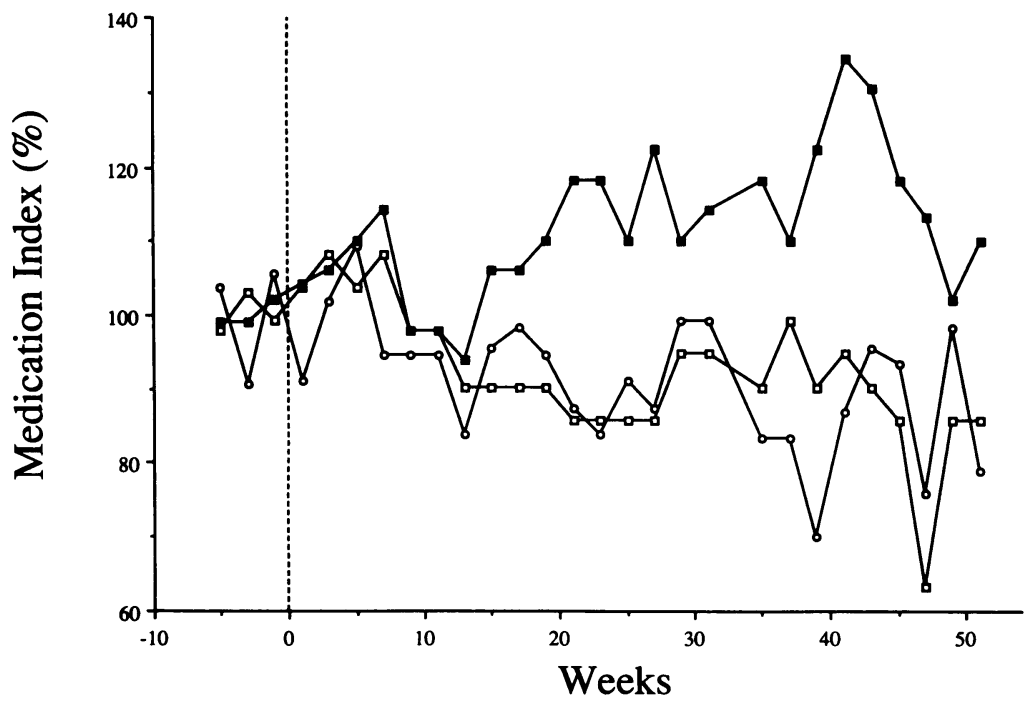

Figure 2. Evolution of medication intake in group A ( $\square$ ), group B (O), and group C ( $\square$ ) patients during the first year of the study. Each point represents the mean of scores averaged over a 2-wk period. Results are expressed as a medication index with a value of $100 \%$ arbitrarily assigned to means of medication intake during the 6-wk prestudy period. 
trated by the evolution of the number of oral corticosteroid courses that had to be taken by the patients. Over the 3-mo period including $6 \mathrm{wk}$ before the trial and the first $6 \mathrm{wk}$ of the trial, the number of steroid courses per patient was $2,0.8$, and 1.2 for groups $\mathrm{A}, \mathrm{B}$, and $\mathrm{C}$, respectively. After the second month of treatment, these figures were $0.17,0.37$, and 1.25 , respectively. Mean intake of inhaled beclomethasone was 500 , 538 , and $538 \mu \mathrm{g} / \mathrm{d}$ over the 6 -wk observation period preceding the beginning of the trial. $90 \%$ of the placebo patients still used inhaled beclomethasone during the study (mean intake 700 $\mu \mathrm{g} / \mathrm{d}$ ), but only $40 \%$ of the treated patients had to do so (mean intake $435 \mu \mathrm{g} / \mathrm{d}$ ). $30 \%$ of treated patients were able to do without their medication completely or to use only salbutamol occasionally (score 1), while none of the placebo patients was able to do so. This overall reduction in medication in the treated groups was maintained during the second year of treatment.

$P E F$ and lung function. PEF were measured four times a day, before and after drug inhalation. Values for both minimum and maximum PEF were averaged over 2 wk. Fig. 3 shows the evolution over $2 \mathrm{yr}$ of treatment. This indicates that despite careful patient randomization group A patients had significantly lower values for both minimum and maximum PEF than either of the other groups (Mann-Whitney U test, $P$ $<0.05)$. Nevertheless, their values increased steadily until reaching levels similar to the two other groups after $30 \mathrm{wk}$, even though the treatment frequency was reduced at this stage. Lung function was measured on three occasions, before the study and after 1 and 2 yr. Mean values for FEV 1 in groups $A$, $\mathrm{B}$, and $\mathrm{C}$ were 71,74 , and $88 \%$ at the beginning of the study; 76,78 , and $84 \%$ after $1 \mathrm{yr}$; and 76,74, and $80 \%$ after $2 \mathrm{yr}$, respectively. Corresponding values of total lung volume were 156,143 , and $137 \% ; 143,136$, and $134 \%$; and 155,128 , and $139 \%$. Specific airway conductance was $1.09,0.99$, and 1.34 liters $/ \mathrm{kPa} \cdot \mathrm{s}^{-1}$ at the beginning of the study for groups $\mathrm{A}, \mathrm{B}$, and $C$, respectively; $1.27,1.07$, and 1.22 after $1 \mathrm{yr}$; and 0.96 , 1.4 , and 1.07 at the end of the trial. FEV 1 values were signifi- cantly lower (Mann-Whitney U test, $P<0.05$ ) in group A patients than in group $C$ patients at the beginning of the study.

Skin tests. Intradermal skin tests were performed on three occasions, at the beginning of the trial and after 1 and $2 \mathrm{yr}$ of treatment. Nonspecific skin reactivity was evaluated by the inoculation of histamine at a concentration of $1 \mathrm{mg} / \mathrm{ml}$. Fig. 4 shows the skin wheal area obtained after intradermal inoculation of allergen at different dosages before the study and 1 and $2 \mathrm{yr}$ afterward. Reactivity to $1 \mathrm{mg} / \mathrm{ml}$ histamine was unchanged over the study period (data not shown). A progressive decrease in the wheal area elicited by inoculation of allergen was observed in both groups A and B over the entire concentration range (Wilcoxon matched pair test, $P<0.001$ for both groups at $400 \mathrm{ng}$ allergens $/ \mathrm{ml}$ ). No significant change was detected in the allergen skin reactivity of the placebo group.

Bronchial challenges. Challenges were carried out three times on each patient at exactly 1-yr intervals to avoid the effect of seasonal variations on bronchial hyperreactivity. Only patients able to do without bronchodilators for $12 \mathrm{~h}$ without steroid treatment, and whose basal lung function was at least $75 \%$ of the normal values were challenged. At the beginning and after 1 yr of treatment the number of patients who qualified for such challenges was 5 of 11 in group A, 6 of 13 in group $B$, and 8 of 12 in group C (Fig. 5). After the second year three additional treated patients, one in group $A$ and two in group $B$, could be challenged with Ach. One patient in group A did not come back in time for his second year challenge. Nonspecific bronchial reactivity to Ach was unchanged after 1 or 2 yr of treatment for both treated groups (Wilcoxon matched pair test, $P=\mathrm{NS}$ ). In contrast, a significant increase in reactivity was observed in group $\mathrm{C}$ patients (Wilcoxon matched pair test, $P<0.05)$.

Allergen provocation tests were carried out $24 \mathrm{~h}$ after Ach provocation, ensuring first that the basal lung function was $\geq 75 \%$ of normal values. Fig. 6 shows the bronchial allergen sensitivity before the study and after 1 and 2 yr of treatment. As numbers of paired data are small, statistical significance
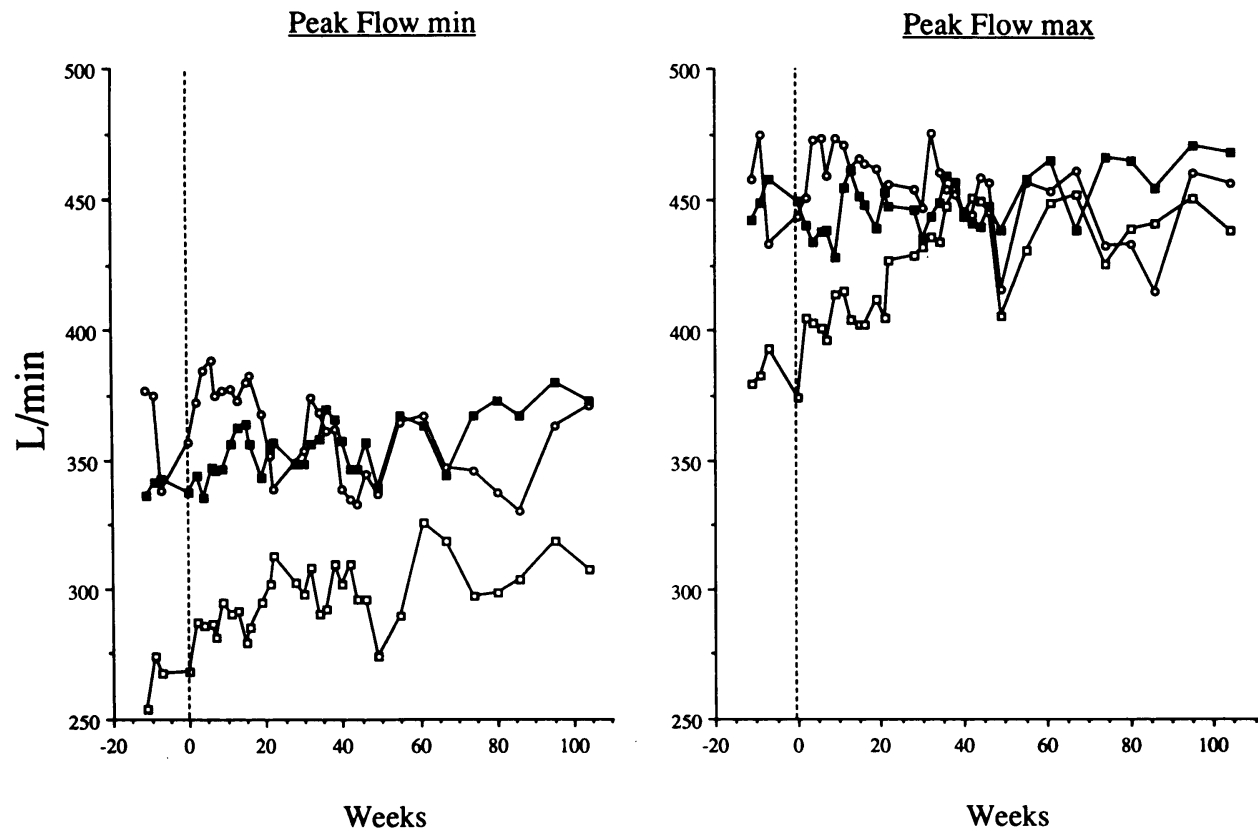

Figure 3. Evolution of PEF in group A (口), group B (o), and group C ( $\square)$ patients over 2 yr of treatment. Each point represents the mean of two daily measurements of either minimum PEF or maximum PEF averaged over a 2 -wk period. 

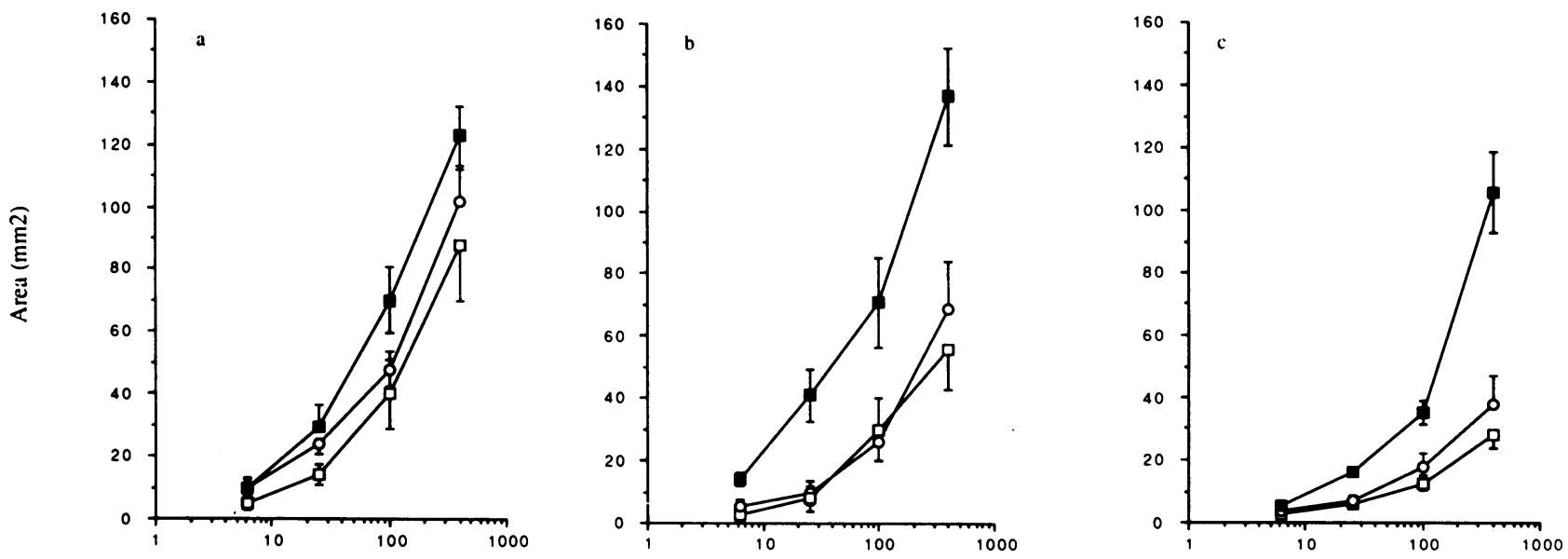

$\mathrm{Dpt}(\mathrm{ng} / \mathrm{ml})$

Figure 4. Skin wheal area obtained after intradermal inoculation of $20 \mu \mathrm{l}$ of Dpt allergens at four different concentrations. $a$, Skin reactivity before the study period; $b$, reactivity $1 \mathrm{yr}$ after the beginning of the trial; $c$, reactivity after the second year. Nonspecific skin reactivity was measured by inoculation of $1 \mathrm{mg}$ histamine/ml with no significant change over the study period. $\square$, Group A patients; $\bigcirc$, group B patients; $\square$, group C patients.

should be considered with caution. Nevertheless, by applying the Wilcoxon matched pair test, a significant $(P<0.05)$ reduction of sensitivity was found in group A between November 1985 and November 1986, November 1985 and November 1987, and November 1986 and November 1987. In group B the same level of significance was observed between November 1985 and November 1987. The maximum Dpt concentration used was $1 \mu \mathrm{g} / \mathrm{ml}$; patients with data points at this level were considered to show complete loss of sensitivity to specific challenge. Thus, at the 2-yr observation period, three of six patients in group A were no longer reactive, one exhibited a significant reduction in sensitivity, and one showed essentially no change in reactivity. The sixth patient of this group had shown complete loss of reactivity at the 1-yr challenge. In group B, at the 2-yr observation period two of six patients had lost allergen sensitivity, two had improved signifcantly, one was unchanged, and one had deteriorated with respect to initial values. No significant changes were seen in group $\mathrm{C}$ after either the first or second year of treatment, although three of eight patients were less reactive to allergen inhalation after $1 \mathrm{yr}$. Two subsequently resumed their initial reactivity, and at the end of the second year only two had a
Group A

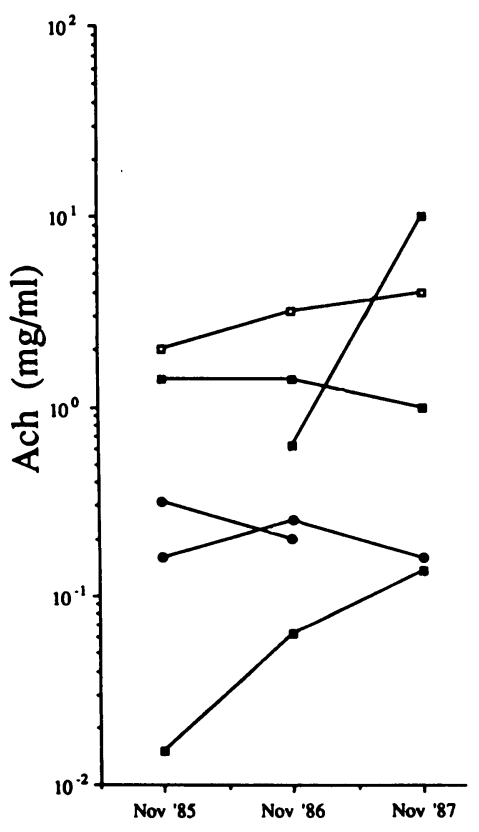

Group B

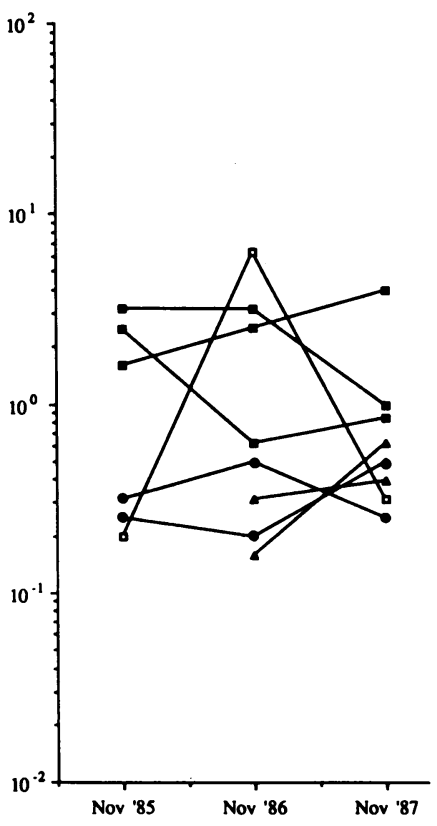

\section{Placebo}

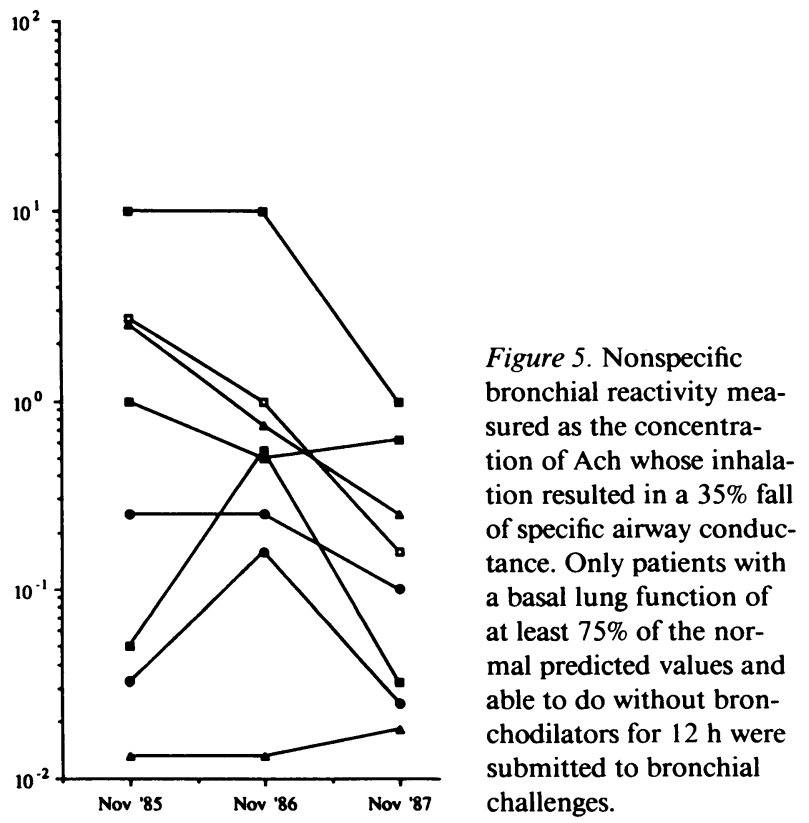


Group A

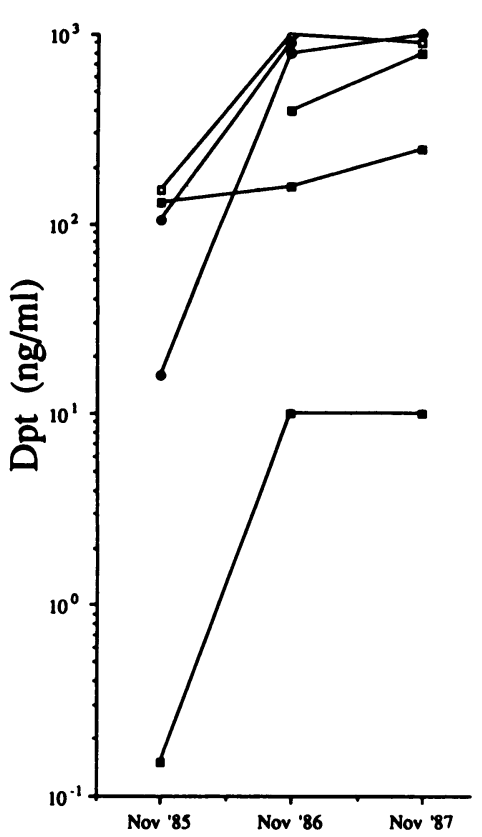

Group B

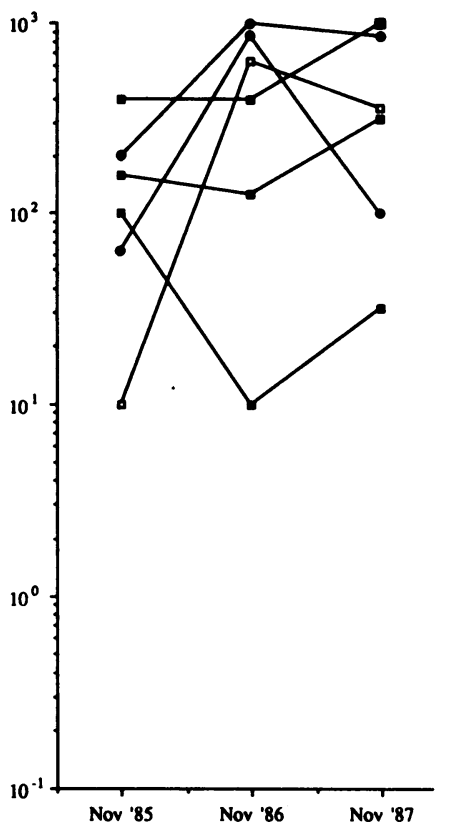

Placebo

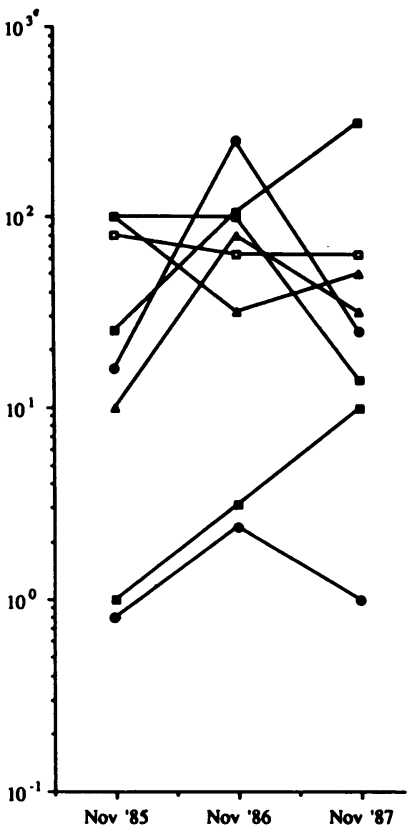

Figure 6. Specific bronchial reactivity measured as the concentration of Dpt whose inhalation resulted in a $35 \%$ fall of specific airway conductance. Patients not responding to a concentration of $1 \mu \mathrm{g} / \mathrm{ml}$ are considered as having completely lost their reactivity. Higher dosages of allergen produce nonspecific lung function impairment in a significant proportion of nonallergic individuals. significant reduction in allergen sensitivity. None of the placebo patients had completely lost bronchial specific reactivity. No significant difference was seen between the two treated groups, but both differed from the placebo group after either the first or second year of treatment (Mann-Whitney U test, $P<0.05$ in each case).

Specific antibodies. Specific IgE and IgG antibodies were quantified after their adsorption and elution from Dpt-Sepharose and are shown in Fig. 7. Values are expressed as serum concentration and plotted logarithmically. At the beginning of the study, concentrations of specific IgE or specific IgG antibodies were respectively similar in each group. In both groups
A and B, specific IgE antibodies declined steadily; the initial IgE increase usually encountered with free allergen inoculation was absent. By the 10th week all treated patients showed a significant reduction of IgE concentrations. In contrast, none of the placebo patients showed a decline in specific IgE; the concentration remained stable during the entire study period. A small but homogeneous increase of IgE concentration was nevertheless observed when allergen exposure was at its highest, corresponding to the last months of Autumn. Fig. 8 shows the changes in individual specific IgE values between the beginning and end of the study. Each point is the mean of three estimates made on different serum samples. A significant de-

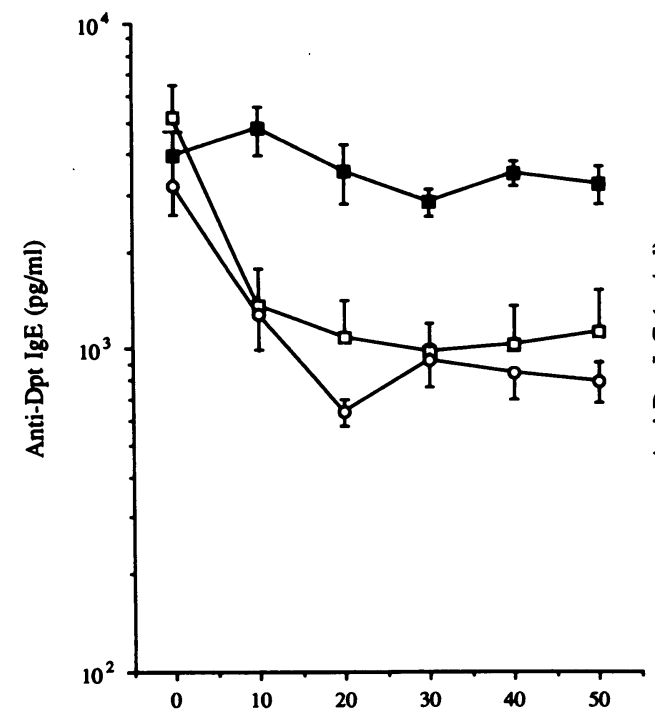

WEEKS

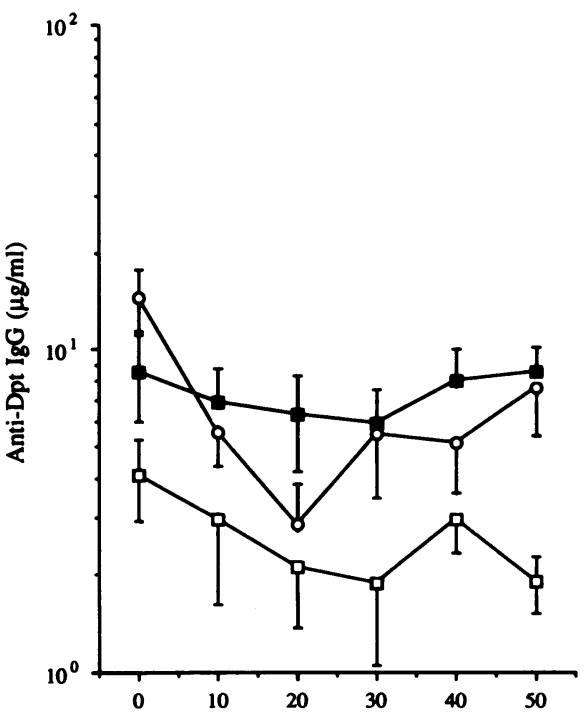

WEEKS
Figure 7. Evolution of specific IgE (left) and specific IgG (right) antibodies in group A ( $\square$ ), group B (O), and group C (ם) patients. Each point represents the mean of antibody concentration of three consecutive samples for each patient in the group considered. Vertical bars give SEM. 

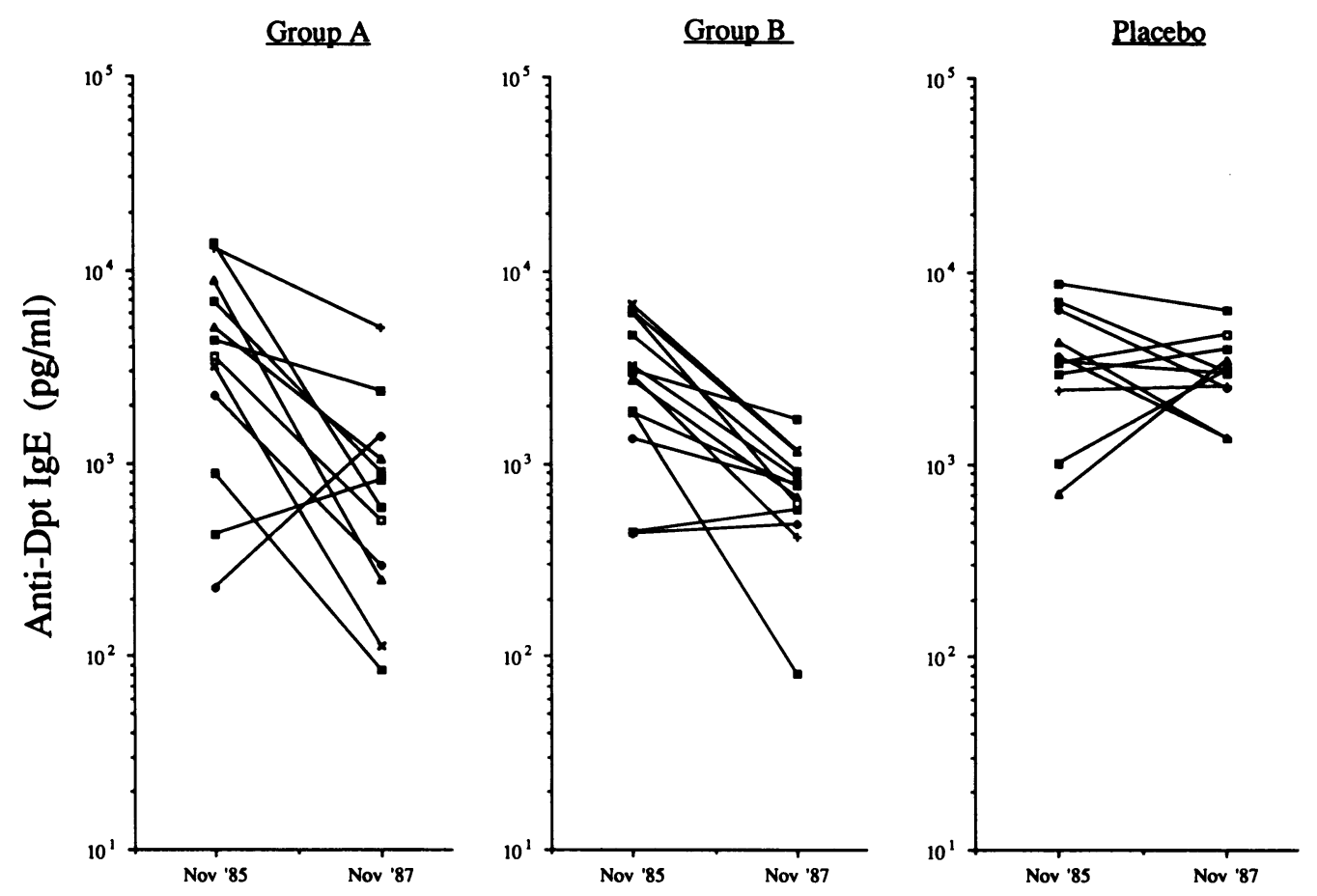

Figure 8. Evolution of individual specific IgE antibodies over the 2-yr study. Each point represents the mean of antibody concentration of three consecutive samples.

cline in specific IgE was seen in both treated groups (Wilcoxon matched pair test, $P<0.01$ ) with no change in the placebo group. Mean IgE concentrations dropped from 5,185 $\pm 1,323$ to $1,123 \pm 489 \mathrm{pg} / \mathrm{ml}$ in group $A$ and from $3,201 \pm 593$ to $792 \pm 112 \mathrm{pg} / \mathrm{ml}$ in group $\mathrm{B}$, corresponding to a fourfold reduction in both cases. In eight treated patients (30\%) serum IgE concentration fell by one log scale. Most of this reduction was already achieved after $10 \mathrm{wk}$ of treatment and maintained thereafter.

A reduction in the serum concentration of specific IgG was observed after $10 \mathrm{wk}$ of treatment. Later in the study, the

concentrations of specific IgG fluctuated but remained below the starting values in most cases. Fig. 9 shows the change in individual specific IgG values between the beginning and end of the study. Each data point is the mean of three estimates made on consecutive serum samples. Six patients in group A showed a significant decrease of specific IgG (Wilcoxon matched pair test, $P<0.02$ ), three had unchanged concentrations, and three had increased concentrations. The overall evolution of specific IgG was not significant in group A. Within patients of group B, 10 patients showed a significant reduction in IgG concentrations, 1 showed unchanged con-
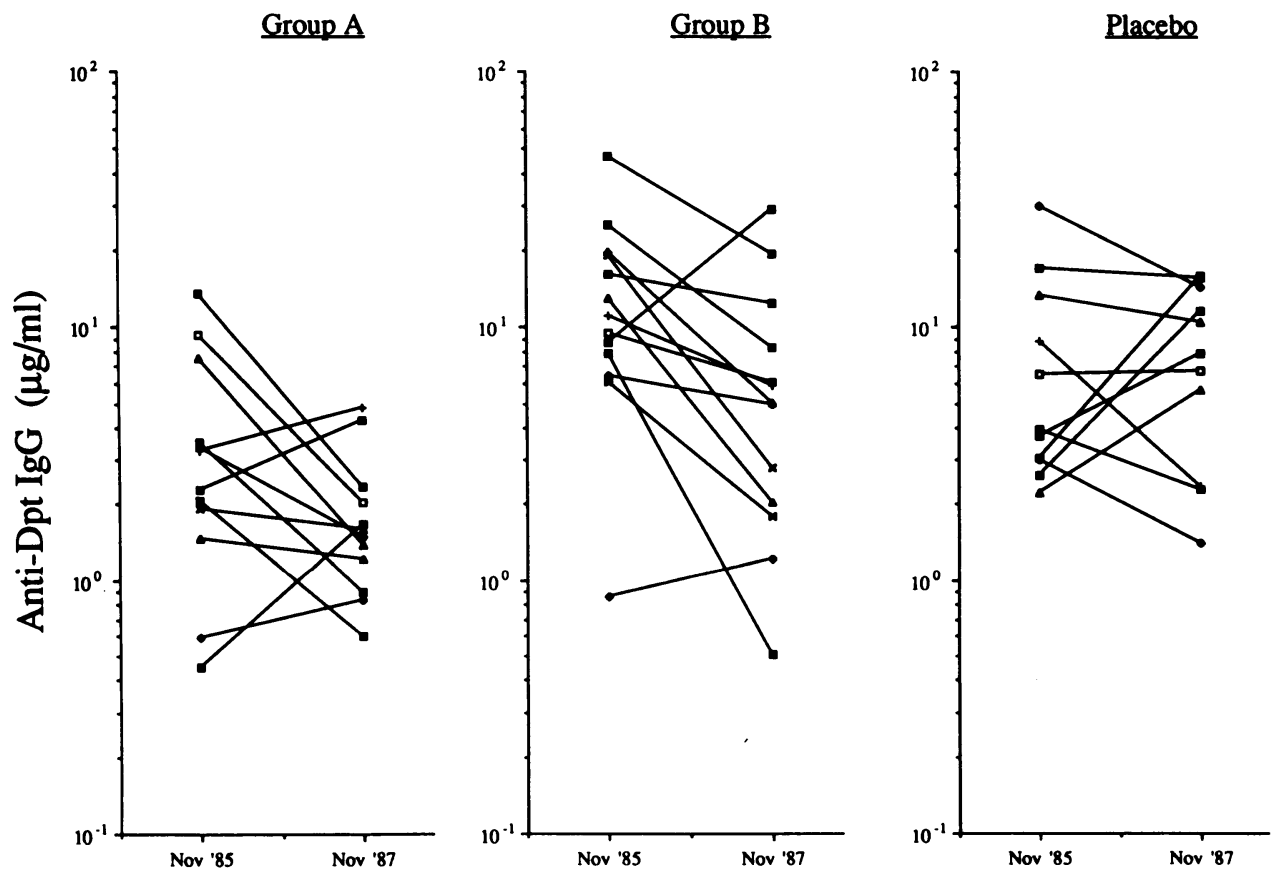

Figure 9. Evolution of individual specific IgG antibodies over the 2-yr study. Each point represents the mean of antibody concentration of three consecutive samples. 
centrations, and 2 had increased concentrations. Group B as a whole had significantly lower IgG concentrations at the end of the trial than initial values (Wilcoxon matched pair test, $P<0.05$ ). In the placebo group, four patients showed an increased IgG concentration, three had unchanged values, and four had a lower concentration, but these changes were not significant. Interestingly, reduction of IgG concentrations of placebo patients occurred later during the study than changes induced by the treatment. A positive correlation was found between the changes in serum $\mathrm{IgE}$ and $\mathrm{IgG}$ antibodies $(r$ $=0.86, P<0.01$ ) (Fig. 10).

Correlation of specific antibody concentrations with other clinical parameters. Finally, we examined the possible relationships of specific antibody concentrations with other parameters. No significant correlation was found between IgE or IgG specific antibody levels and symptoms, drug intake, PEF, skin tests, or specific and nonspecific bronchial challenges.

\section{Discussion}

Inoculation of allergen-antibody complexes results in a fast and significant improvement of bronchial asthma in patients hypersensitive to Dpt. Compared with conventional hyposensitization, this treatment requires 100 -fold less allergen, is probably safer, and relies on a different mechanism of action.

We chose to study the human immune response to Dpt as hypersensitivity to this mite is the most common cause of allergic bronchial asthma in our country (16). Moreover, the main Dpt allergens have been characterized and are available commercially (17). In previous work (Saint-Remy, J. M., and M. G. Jacquemin, unpublished observations) we have demonstrated that mixing allergen with specific antibody in a 1:5 (wt/wt) ratio enabled us to construct complexes in sufficient antibody excess to neutralize the wheal and flare skin reaction elicited by inoculating free allergen in a majority of atopic patients. Although we observed variations from one patient to another in the precise ratio of antigen over antibody necessary to achieve this allergen neutralization effect, it was felt that a 1:5 ratio was an acceptable standard ratio.

As this is the first trial of antigen-antibody complexes in man as far as we are aware, we felt bound, for obvious ethical reasons, to first study patients whose clinical status had not improved by either pharmacologic or immunologic treatment. Hence, patients included in this trial were suffering from multifactorial chronic bronchial asthma which necessitated continuing medication, and in whom conventional immunotherapy had not succeeded. Although we understood that such selection criteria could introduce a study bias, we considered that the biggest drawback would be to mask the effects of treatment with antigen-antibody complexes and thus, if anything, underestimate its impact. The study was therefore designed to answer two questions. First, would the treatment lead to a reduction in the medication needed by these patients to stay as symptom-free as possible? To optimize patient compliance and continued participation in the trial, we favored this aspect of the study design rather than trying to impose a general reduction in medication intake. Second, would the treatment induce alterations in parameters of immediate hypersensitivity, e.g., skin tests and specific bronchial provocation tests or serum concentration of specific antibodies?

With regard to the double-blind design of this study, the immediate skin reactivity resulting from inoculation in some treated patients might have introduced a bias. Addition of histamine to the placebo solution was not considered as it would have permitted identification of the placebo group as soon as the skin reactivity of treated patients had disappeared. As only a proportion of treated patients had an immediate skin reactivity, the latter being present only during the first weeks of the trial, and as some of the placebo patients experienced local pruritus and erythema, it is unlikely that the clinician was able to guess patient group allocation. In addition, the clinical evaluation was based on the patients' own records and the decision to adjust drug treatment on daily measurements of PEF. Both clinical and biological data were analyzed blindly by one of us

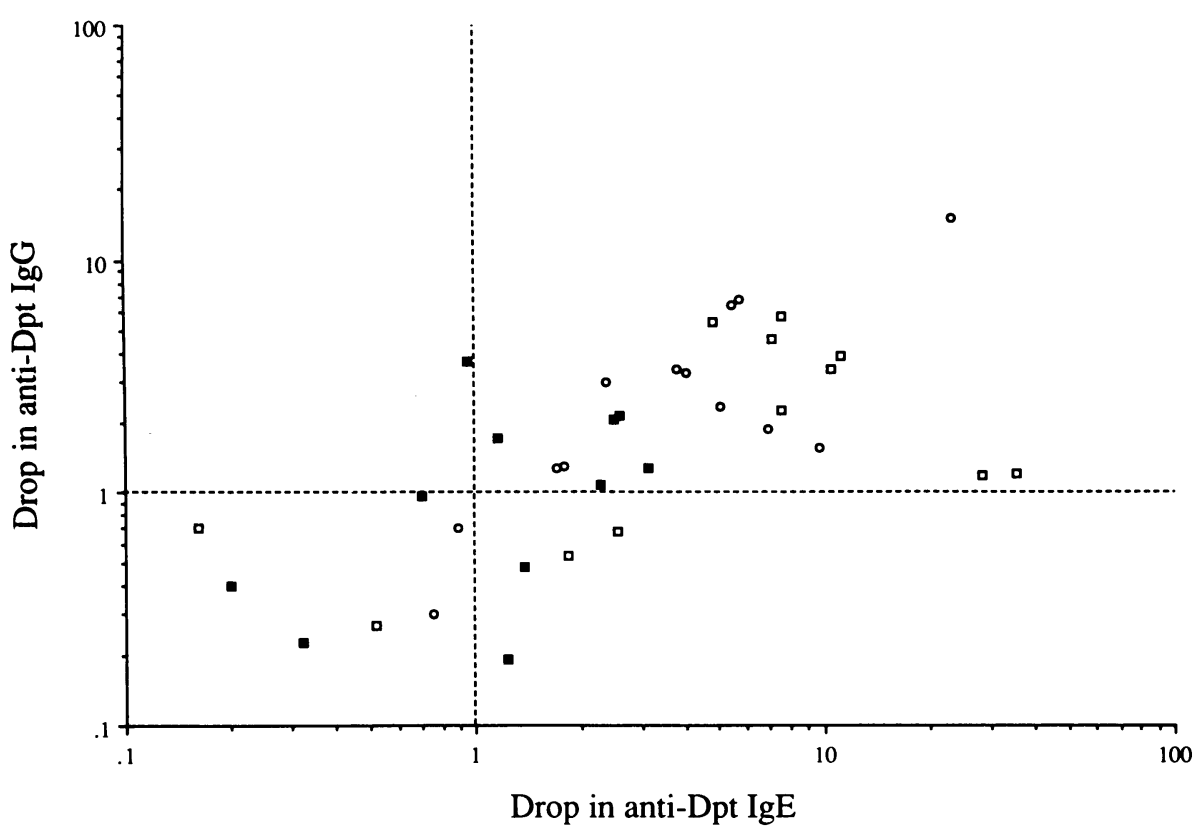

Figure 10. Relationship between evolution of specific IgE and specific IgG antibodies in group A (), group B (O), and group C (a) patients $(r=0.86$ by Spearman's rank correlation test, $P<0.001$ ). Each point represents the ratio of specific IgG or IgE antibody concentration evaluated before the treatment and $2 \mathrm{yr}$ afterward. A value of 1 indicates no change in antibody titer, a value of 10 represents a 10 -fold reduction, and a value of 0.1 indicates an actual 10 -fold increase in antibody concentrations. 
(M.S.), independent of the clinician. Finally, bronchial challenges were performed by an independent technician and results automatically computerized.

Significant reduction in medication intake was achieved after the fourth month of treatment. A 10- and 2-fold reduction in the use of oral corticosteroids was observed in group $A$ and B patients, respectively, which corresponded to seven and three times less than placebo patients. Inhaled beclomethasone was also used significantly less'by group A and B patients, but we think that the most startling feature of this trial is the fact that $30 \%$ of treated patients were able to completely discontinue their medication or to use beta $a_{2}$-agonists only occasionally. This, together with the definite symptomatic improvement of patients, was unexpected. Indeed, the patient selection criteria used meant that only chronic asthma patients, in whom bronchial symptoms were triggered by nonallergic factors such as exercise, respiratory infection, or irritant inhalation, were included in this study. This suggests that even in disease states as multifaceted as chronic asthma, IgE-mediated reactions could continue to play a prominent role. A recent report (18) points out that, irrespective of the actual triggering factors of their asthma, a vast majority of asthmatic patients have elevated concentrations of IgE antibodies, suggesting that the concept of intrinsic asthma, as opposed to extrinsic asthma, may not be justified.

In a majority of patients a first clinical improvement was noted after the 10th week of treatment. Together with observations made in grass pollen hypersensitive patients, ${ }^{2}$ this suggests that either a threshold dose of antigen-antibody complexes has to be reached before a clinical improvement can be noted, or that this time interval is necessary to reduce specific IgE concentration in tissues below the value at which mast cells can degranulate in the presence of the relevant allergen. It is likely that both aspects are relevant. The time delay between start of treatment and appearance of clinical improvement can be reduced to four weeks if injections are made over a few days instead of weeks (Machiels, J. J., P. M. Lebrun, and J. M. R. Saint-Remy, unpublished observations).

Comparison between the two groups of treated patients indicates that no significant clinical, functional, or biological differences can be discerned between groups A and B. However, the majority of patients who were able to do without their medication belonged to group B, receiving the lower dosage. The same group B patients had a lower clinical score than group A patients at the end of the study. Numbers are too small to evaluate the significance of these findings, but it is still interesting to recall that, for the entire treatment, the amount of allergen used in group B was sixfold lower than in group A. This contrasts with conventional hyposensitization where clinical improvement is dependent on highest doses of allergens (19).

Bronchial challenge with allergen is a valuable quantitative means of evaluating the benefit of a treatment (20) although the procedure remains cumbersome and somewhat hazardous, and cannot be considered as an exact model of bronchial asthma (21). Our study design led us to measure bronchial reactivity at intervals of exactly one year to eliminate seasonal

2. Machiels, J. J., M. A. Somville, P. M. Lebrun, S. J. Lebecque, M. G. Jacquemin, and J. M. R. Saint-Remy, manuscript submitted for publication. variations. However, because of this constraint the number of patients who could be challenged was reduced, since either basal lung function was not satisfactory after discontinuation of drug or the patients were unable to withhold medication long enough to comply with the protocol. Treated patients who were challenged after one or two years had a parallel clinical and biological evolution to those who were not tested. This might suggest that bronchial specific reactivity was reduced in every treated patient. It might also be that reduction or loss in bronchial reactivity to the allergen occurred earlier during the study; bronchial reactivity has indeed been correlated to serum-specific IgE antibodies (22). In contrast to the marked reduction in allergen sensitivity, nonspecific bronchial reactivity was not reduced or was only marginally reduced at the end of the second year of treatment. The question whether this nonspecific hyperreactivity could also be diminished over a longer term remains open, although additional observations (Machiels, J. J., P. M. Lebrun, M. G. Jacquemin, and J. M. R. Saint-Remy, manuscript in preparation) would suggest that it could well be the case in some patients.

Late bronchial reactivity is considered a more relevant parameter than immediate reactivity to follow up hyposensitization efficacy (23), but can only be performed in patients requiring no treatment when they are not exposed to allergen. In this study late reactivity could not be evaluated since the medication had to be resumed shortly after the challenge. Nevertheless, none of the treated patients who were able to discontinue their symptomatic treatment experienced a fall in PEF on the day after bronchial challenge, regardless of the presence or absence of an immediate reaction to challenge. In contrast, placebo patients exhibited a significant drop in PEF requiring temporary increase in medication on the day after challenge.

There are at least three reasons why this treatment is likely to be safer than usual hyposensitization. First, considerably less allergen is used for the treatment. For instance, the total amount of Dpt inoculated during a standard hyposensitization treatment would be $350 \mu \mathrm{g}$, with an average of 20 injections to reach the maintenance dosage. In this study, the amounts of allergen for the same number of injections was $3.2 \mu \mathrm{g}$ in group $\mathrm{A}$ and $1 \mu \mathrm{g}$ in group B. Second, antibodies present in the complexes inhibit efficiently the binding of specific IgE antibodies to Dpt allergens in vivo (12). We have, however, shown that anti-Dpt IgG do not bind to the same epitopes of Dpt allergens as do specific IgE (24). It is therefore likely that inhibition occurs by steric hindrance. Third, the intradermal route instead of the usual subcutaneous one limits the allergen diffusion rate after inoculation. The excellent tolerance to treatment and the absence of any systemic side-effects bear out these observations.

Our observations made on specific antibodies diverge from findings associated with conventional hyposensitization for several reasons. First, we did not see an early increase in IgE concentrations, which is generally induced by hyposensitization. Second, a major reduction in IgE concentrations occurred early, reaching significance after only $10 \mathrm{wk}$ of treatment. Third, specific IgG concentrations were not raised as a result of treatment. This obviously questions the importance of specific IgG antibodies in the immunologic treatment for immediate hypersensitivity to airborne allergens. In hyposensitization trials an inverse relationship can sometimes be found between specific IgG and IgE antibodies (25). In the present study we found a parallel decrease in both antibodies. 
These findings also argue for a different mechanism of action for these two treatments.

The methods used to assay serum-specific IgE or IgG antibodies in this study differ from those used in other studies but were used to allow both a careful follow-up of IgG antibodies and an evaluation of other parameters like anti-idiotypic and anti-isotypic antibodies (24). Anti-allergen IgG antibodies are difficult to assay in serum since they represent a very small percentage of the total IgG. Existing methods (26) have been found difficult to use by other investigators. Our methodology has been critically reviewed and found suitable for this application (12). Samples were applied to the column in a random order and were checked for completeness of adsorption. Conditions used for elution of bound antibodies from the column were optimized using radiolabeled specific antibodies. Moreover, in another study using similar allergen-antibody complexes, ${ }^{2}$ serum IgG antibodies were titrated by an independent laboratory (Prof. F. Atkinson, Johns Hopkins University, Baltimore, MD) and found to remain below the lower level of sensitivity throughout the trial. In the same study we also evaluated our technique of IgE antibody titration by comparing it with two other assays for serum IgE, the radioallergosorbent test and a latex agglutination test developed in our laboratory (27).

The mechanism by which allergen-antibody complexes operate is at present unknown. Such complexes are potent inducers of anti-idiotypic antibodies (28), which are capable of suppressing in vitro IgE production (29). We and others (30, 31) have demonstrated the presence of spontaneously produced anti-idiotypic antibodies specific to anti-allergen antibodies. More work is required to understand the mechanism of action, but we are convinced of both the clinical and experimental interests of this treatment.

Finally, we have considered that the clinical effect resulting from inoculation of allergen-antibody complexes might be attributable either to low doses of allergen or to specific antibodies. This question has been examined in two other clinical studies. First, bronchial asthma related to grass pollen exposure was not prevented by injections of allergen alone, whereas inoculation of allergen-antibody complexes was efficient (Machiels, J. J., P. M. Lebrun, M. A. Somville, M. G. Jacquemin, and J. M. R. Saint-Remy, manuscript in preparation). Second, in another study on Dpt hypersensitivity (Machiels, J. J., M. A. Somville, S. J. Lebecque, M. G. Jacquemin, and J. M. R. Saint-Remy, manuscript in preparation), comparison of patients treated with specific antibodies alone with a group inoculated with allergen-antibody complexes showed no benefit from antibody inoculation.

\section{Acknowledgments}

The authors thank Thérèse Briet, Edwige Hanssens and Yves Delmarcelle for excellent technical assistance, Alan Barclay for critical review of the manuscript, and Brigitte Firket for secretarial help. This work was supported by a Baxter grant.

\section{References}

1. Ishizaka, $K$., and T. Ishizaka. 1967. Identification of $\gamma \mathrm{E}$ antibodies as a carrier of reaginic activity. J. Immunol. 99:1187-1198.

2. Rousset, F., R. de Waal Malefijt, B. Slierendregt, J. P. Aubry, J. Y. Bonnefoy, T. Defrance, J. Banchereau, and J. E. de Vries. 1988.
Regulation of Fc receptor for IgE (CD23) and class II MHC antigen expression on Burkitt's lymphoma cell lines by human IL-4 and IFNgamma. J. Immunol. 140:2625-2632.

3. Marsh, D. G., L. M. Lichtenstein, and D. H. Campell. 1970. Studies on 'allergoids' prepared from naturally occurring allergens. I. Assay of allergenicity and antigenicity of formalinized rye group I component. Immunology. 18:705-722.

4. Lee, W. Y., and A. H. Sehon. 1976. Suppression of reaginic antibody formation. IV. Suppression of reaginic antibodies to penicillin in the mouse. J. Immunol. 117:927-934.

5. Klaus, G. G. B. 1979. The role of antigen-antibody complexes in generating immunological memory and auto-anti-idiotypic immunity. Adv. Exp. Med. Biol. 114:289-294.

6. Sinclair, N. R., and A. Panoskaltsis. 1987. Immunoregulation by Fc signals. Immunol. Today. 8:76-79.

7. Tite, J. P., C. A. Morrison, and R. B. Taylor. 1982. Immunoregulatory effects of covalent antigen-antibody complexes. IV. Priming and tolerance in T-dependent responses. Immunology. 46:809-817.

8. Heyman, B., and H. Wigzell. 1984. Immunoregulation by monoclonal sheep erythrocyte-specific IgG antibodies: suppression is correlated to level of antigen binding and not to isotype. J. Immunol. 132:1136-1143.

9. Caulfield, M. J., and D. Shaffer. 1987. Immunoregulation by antigen-antibody complexes. I. Specific immunosuppression induced in vivo with immune complexes formed in antibody excess. J. Immunol. 138:3680-3683.

10. Blaser, K., T. Nakagawa, and A. L. de Weck. Suppression of the benzylpenicilloyl (BPO) specific IgE formation with isologous antiidiotypic antibodies in BALB/c mice. J. Immunol. 125:24-30.

11. Lichtenstein, L. M., P. S. Norman, and W. L. Winkenwerder. 1971. A single year of immunotherapy for ragweed hay fever: immunologic and clinical studies. Ann. Intern. Med. 75:663-671.

12. Saint-Remy, J. M. R., P. M. Lebrun, S. J. Lebecque, and P. L. Masson. 1988. Human immune response to allergens of house dust mite, Dermatophagoides pteronyssinus: isotypic analysis of antibodies in atopic and non-atopic subjects. Allergy (Copenh.). 43:338-347.

13. Magnusson, C. G. M., D. Collet-Cassart, T. G. Merrett, and P. L. Masson. 1981. An automated particle counting immunoassay (PACIA) for serum IgE. Clin. Allergy. 11:453-461.

14. Dolovich, J., and F. E. Hargreave. 1981. Strategies in the control of asthma. Med. Clin. North Am. 65:1033-1043.

15. Machiels, J., and A. Ferrière. 1983. Bronchial response to acetyl-choline and Dermatophagoides pteronyssinus in asymptomatic asthma. Bull. Eur. Physiopathol. Respir. 19:483-488.

16. Voorhorst, R., F. T. M. Spieksma, H. Varekamp, M. J. Leupen, and A. W. Lyklema. 1967. The house dust mite (Dermatophagoides pteronyssinus) and the allergens it produces: identity with the house dust allergen. J. Allergy. 39:325-339.

17. Platts-Mills, T. A. E., and M. D. Chapman. 1987. Dust mites: immunology, allergic disease, and environmental control. J. Allergy Clin. Immunol. 80:755-775.

18. Burrows, B., F. D. Martinez, M. Halonen, R. A. Barbee, and M. G. Cline. 1989. Association of asthma with serum IgE levels and skin-test reactivity to allergens. N. Engl. J. Med. 320:271-277.

19. Creticos, P. S., and P. S. Norman. 1987. Immunotherapy with allergens. JAMA (J. Am. Med. Assoc.). 258:2874-2880.

20. Fish, J. E., and J. F. Kelly. 1979. Measurements of responsiveness in bronchoprovocation testing. J. Allergy Clin. Immunol. 64:592-596.

21. Platts-Mills, T. A. E., P. W. Heymann, M. D. Chapman, and E. B. Mitchell. 1985. Bronchial hyper-reactivity and allergen exposure. Prog. Respir. Res. 19:276-284.

22. Cockcroft, D. W., R. E. Ruffin, P. A. Frith, A. Cartier, E. F. Juniper, J. Dolovich, and F. E. Hargreave. 1979. Determinants of allergen-induced asthma: dose of allergen, circulating IgE antibody concentration, and bronchial responsiveness to inhaled histamine. Am. Rev. Respir. Dis. 120:1053-1058. 
23. Kaliner, M. M. 1984. Hypotheses on the contribution of latephase allergic responses to the understanding and treatment of allergic diseases. J. Allergy Clin. Immunol. 73:311-319.

24. Saint-Remy, J. M. R., S. J. Lebecque, P. M. Lebrun, and M. G. Jacquemin. 1988. Human immune response to allergens of house dust mite, Dermatophagoides pteronyssinus. IV. Occurrence of natural autologous anti-idiotypic antibodies. Eur. J. Immunol. 18:83-87.

25. Lichtenstein, L. M., K. Ishizaka, P. S. Norman, A. K. Sobotka, and B. M. Hill. 1973. IgE antibody measurements in ragweed hay fever. Relationship to clinical severity and the results of immunotherapy. J. Clin. Invest. 52:472-482.

26. Hamilton, R. G., A. K. Sobotka, and N. F. Adkinson. 1979. Solid-phase radioimmunoassay for quantitation of antigen-specific IgG in human serum with ${ }^{125}$ I-protein A from Staphylococcus aureus. J. Immunol. 122:1073-1079.

27. Gilles, J. G. G., J. C. P. Mareschal, and J. M. R. Saint-Remy.
1988. Latex allergosorbent test (LAST): A new immunoassay for specific IgE with latex particles. J. Allergy Clin. Immunol. 82:35-39.

28. Klaus, G. G. B. 1978. Antigen-antibody complexes elicit antiidiotypic antibodies to self-idiotopes. Nature (Lond.). 272:265-266.

29. Geha, R. S., and M. Comunale. 1983. Regulation of immunoglobulin $\mathrm{E}$ antibody synthesis in man by anti-idiotypic antibodies. $J$. Clin. Invest. 71:46-54.

30. Saint-Remy, J. M. R., S. J. Lebecque, P. M. Lebrun, and M. G. Jacquemin. 1988. Human immune response to allergens of house dust mite, Dermatophagoides pteronyssinus. V. Auto-anti-idiotypic antibody characterization and cross-reactivity. Eur. J. Immunol. 18:10091014.

31. Bose, R., D. G. Marsh, J. Duchateau, A. H. Sehon, and G. Delespesse. 1984. Demonstration of auto-anti-idiotypic antibody cross-reacting with public idiotypic determinants in the serum of ryesensitive allergic patients. J. Immunol. 133:2474-2478. 